\title{
Laparoscopic-assisted vaginal hysterectomy and the hyperglycemic response to surgery: an obser- vational study
}

[L'hystérectomie vaginale avec assistance laparoscopique et la réponse

hyperglycémique à l'intervention chirurgicale : une étude par observation]

Ralph Lattermann MD, ${ }^{*}$ Thomas Schricker MD PhD, ${ }^{*}$ Ulrich Wachter, $\dagger$ Michael Georgieff MD PhD,$\dagger$ Markus Schreiber MD†

Purpose: To test the hypothesis that laparoscopic-assisted vaginal hysterectomy $(\mathrm{LAVH})$ attenuates the hyperglycemic response to surgery when compared to vaginal hysterectomy $(\mathrm{VH})$.

Methods: Fourteen patients received either $\mathrm{LAVH}(n=7)$ or $\mathrm{VH}$ $(n=7)$. Whole body glucose production was measured before and three hours after surgery using $\left[6.6{ }^{2} \mathrm{H}_{2}\right]$ glucose. Before, during and after the operation, plasma concentrations of glucose, insulin, glucagon, cortisol, epinephrine and norepinephrine were determined.

Results: Plasma glucose concentration increased in both groups during and after surgery showing a significantly higher value after $\mathrm{VH}$ than after LAVH $\left(\mathrm{VH}: 8.3 \pm 1.4 \mathrm{mmol} \cdot \mathrm{L}^{-1}\right.$; LAVH: $6.6 \pm 0.9$ $\left.\mathrm{mmol} \cdot \mathrm{L}^{-1}, P<0.05\right)$. The postoperative increase in glucose production was comparable in both groups. While plasma concentrations of insulin and glucagon remained unchanged, intra- and postoperative plasma cortisol concentrations were significantly higher in the $\mathrm{VH}$ group than in the LAVH group. Plasma catecholamine concentrations significantly increased after both types of surgery to the same extent.

Conclusion: In this observational study, LAVH appears to blunt the hyperglycemic and cortisol response to surgery when compared to $\mathrm{VH}$.

Objectif : Vérifier l'hypothèse selon laquelle l'hystérectomie vaginale avec assistance laparoscopique (HVAL), comparée à l'hystérectomie vaginale $(H V)$, diminue la réponse hyperglycémique à l'intervention chirurgicale.

Méthode : Quatorze patientes ont subi une HVAL $(n=7)$ ou un HV $(n=7)$. La production corporelle totale de glucose a été mesurée avant l'opération et trois heures après au moyen de glucose [6,6-2 $\left.\mathrm{H}_{2}\right]$. Avant, pendant et après l'opération, les concentrations plasmatiques de glucose, d'insuline, de glucagon, de cortisol, d'épinéphrine et de norépinéphrine ont été déterminées.

Résultats : La concentration plasmatique de glucose a augmenté chez les patientes des deux groupes pendant et après l'opération. affichant une valeur significativement plus élevée après l'HV qu'après I'HVAL (VH : 8,3 $\pm 1,4 \mathrm{mmol} \cdot \mathrm{L}^{-1} ; \mathrm{HVAL}: 6,6 \pm 0,9 \mathrm{mmol} \cdot \mathrm{L}^{-1}, \mathrm{P}$ $<0,05)$. L'augmentation postopératoire de production de glucose était comparable d'un groupe à l'autre. Les concentrations d'insuline et de glucagon sont demeurées les mêmes, mais celles du cortisol peropératoire et postopératoire ont été significativement plus élevées chez les patientes du groupe HV comparé au groupe HVAL. Les concentrations de catécholamine ont augmenté de façon significative, et avec la même importance, après les deux types d'opérations.

Conclusion : Cette étude par observation semble indiquer que l'HVAL, comparée à l'HV, diminue la réponse du glucose et du cortisol à l'intervention chirurgicale.

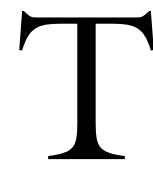

$\mathrm{HE}$ increase in glucose plasma concentration is a typical feature of the body's metabolic response to surgery. ${ }^{1}$ This hyperglycemic response has been shown to depend on the severity of surgical tissue trauma with minimal invasive techniques being less stimulating than corresponding open procedures. ${ }^{2}$ In the early 1990s laparoscopic assisted vaginal hysterectomy (LAVH) was introduced

From the Department of Anesthesia, ${ }^{*}$ McGill University, Montreal, Quebec, Canada, and the Clinic of Anesthesiology, $\dagger$ University of Ulm, Ulm, Germany.

Address correspondence to: Dr. Thomas Schricker, Department of Anesthesia, McGill University, Royal Victoria Hospital, Room S5.05, 687 Pine Avenue West, Montreal, Quebec H3A 1Al, Canada. Phone: 514-842-1231, ext. 5950; Fax: 514-843-1723; E-mail: mbek@musica.mcgill.ca

Accepted for publication May 16, 2001.

Revision accepted July 9, 2001. 
into clinical practice as a surgical alternative to the classical transvaginal and transabdominal approaches. ${ }^{3}$ Although LAVH has been associated with benefits such as better postoperative pain control and shorter length of hospital stay, ${ }^{4}$ its impact on perioperative metabolic and hormonal responses has received little attention. The purpose of the present study was to test the hypothesis that LAVH attenuates the hyperglycemic and endocrine response to surgery when compared to vaginal hysterectomy $(\mathrm{VH})$.

\section{Methods}

After approval from the Ethics Committee of the hospital written informed consent was obtained from 14 consecutive patients undergoing elective hysterectomy for benign uterine myoma. None of the participants was suffering from cardiac, hepatic, renal or metabolic disorders or taking any medication. Patients received either LAVH $(n=7)$ or VH $(n=7)$. The assignment to either treatment was not performed at random but, for ethical reasons, followed the judgement of the gynecologist. Patients with anticipated long duration of surgery (ovarian pathology, previously known dense adhesions, inaccessible uterus) or history of pelvic inflammatory disease were not admitted to the study protocol.

\section{Anesthesia}

All patients received premedication $(20 \mathrm{mg}$ chlorazepate $p o$ ) at 10:00 p.m. the night prior to surgery and at 6:00 a.m. on the day of the operation. In both groups, anesthesia was induced with $5 \mathrm{mg} \cdot \mathrm{kg}^{-1}$ thiopentone and $1.5 \mathrm{\mu g} \cdot \mathrm{kg}^{-1}$ fentanyl and the trachea was intubated after neuromuscular block with 1.5 $\mathrm{mg} \cdot \mathrm{kg}^{-1}$ succinylcholine. The patients' lungs were ventilated with $30 \%$ oxygen in nitrous oxide at a respiratory rate of 10 breaths $\mathrm{min}^{-1}$ to maintain normocapnia (35-40 $\mathrm{mmHg})$. Anesthesia was maintained using enflurane at inspiratory concentrations required to keep heart rate and mean arterial pressure within $20 \%$ of pre-induction values. The degree of muscle relaxation was monitored by using the train-of-four ratio and supplemental doses of vecuronium were applied as needed for complete surgical muscle relaxation. Patients received a balanced electrolyte solution at a rate of $8 \mathrm{~mL} \cdot \mathrm{kg}^{-1} \cdot \mathrm{hr}^{-1}$ during surgery and at $2-4$ $\mathrm{mL} \cdot \mathrm{kg}^{-1} \cdot \mathrm{hr}^{-1}$ thereafter. No patient required red blood cells or colloids. Postoperative pain intensity was quantified using a visual analog scale (VAS, from 0 to 10 , where $0=$ no pain and $10=$ worst imaginable pain) and piritramide (a synthetic opioid with a potency similar to morphine) iv was administered in order to keep VAS below four.
Hemodynamic monitoring was performed using a three-lead electrocardiogram monitor and automatic blood pressure measurement. Cardiac output was measured using thoracic bioimpedance (noninvasive continuous cardiac output monitor NC-COM 3-R7 ${ }^{\mathrm{TM}}$; Bomed Medical Manufacturing Ltd., Irvine, CA, USA).

\section{Study protocol}

The rate of appearance of glucose ( $\mathrm{R}$ glucose, endogenous glucose production) was determined before and three hours after the operation by stable isotope tracer technique using primed continuous infusion of $\left[6.6-^{2} \mathrm{H}_{2}\right]$ glucose (Masstrace, Woburn, MA, USA). Prior to the infusion study, sterile isotope solutions were prepared by the hospital pharmacy as previously described. ${ }^{5}$

Preoperative measurements were performed after an overnight fast three hours before surgery. After a superficial vein in the dorsum of the hand was cannulated and kept patent with a continuous saline infusion, a second catheter was placed in a superficial vein of the contralateral arm for the infusion of $\left[6.6-{ }^{2} \mathrm{H}_{2}\right]$ glucose. The hand was warmed in a heated air box to achieve arterialization of venous blood, blood samples were obtained to determine basal isotopic enrichment and a priming dose of $4 \mathrm{mg} \cdot \mathrm{kg}^{-1}\left[6.6-^{2} \mathrm{H}_{2}\right]$ glucose was administered followed by continuous infusion of $0.05 \mathrm{mg} \cdot \mathrm{kg}^{-1} \mathrm{~min}^{-1}\left[6.6{ }^{2} \mathrm{H}_{2}\right]$ glucose. After 100 , 110 and $120 \mathrm{~min}$ of preoperative isotope infusion, three arterialized blood samples were drawn for the determination of isotopic enrichment. Sixty minutes after the end of anesthesia, primed continuous infusion of $\left[6.6-{ }^{2} \mathrm{H}_{2}\right]$ glucose was repeated and, in analogy to the preoperative measurement, three arterialized blood samples were taken again after 100, 110 and $120 \mathrm{~min}$ of isotope infusion (Figure).

At $\mathrm{t}=110 \mathrm{~min}$ (preoperative), during the operation (five minutes and $60 \mathrm{~min}$ after skin incision and at skin closure) and at $\mathrm{t}=110 \mathrm{~min}$ (postoperative), additional blood was drawn for the determination of plasma concentrations of glucose and hormones (insulin, glucagon, cortisol, epinephrine, norepinephrine).

\section{Analytical methods}

After glucose was converted to its alpha-D-glucofuranose $1: 2,3: 5$ bis(butane-boronate) 6-acetate compound, the isotopic enrichment of $\left[6.6-{ }^{2} \mathrm{H}_{2}\right]$ glucose was determined by gas chromatography-mass spectrometry in the selected-ion monitoring mode using electron impact ionisation (Hewlett Packard GC 5890, MS 5971, Munich, Germany). ${ }^{5}$ The atom percent excess values (APE) used for the calculation of the glucose production rate was the mean of the three 


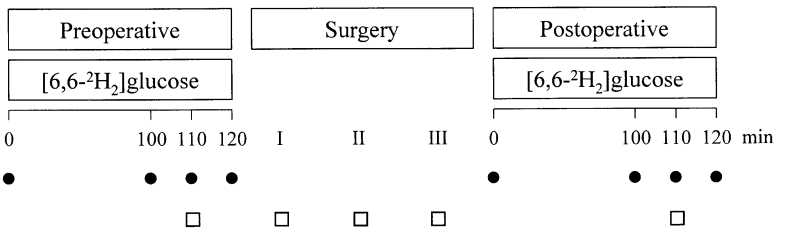

FIGURE Time course of the infusion of $\left(6.6^{2} \mathrm{H}_{2}\right)$ glucose and collection of blood for the pre- and postoperative measurement of isotopic enrichment $(\bullet)$. Sampling times for the determination of plasma concentrations of glucose and hormones $(\square)$ before, during ( $\mathrm{I}=$ five minutes, $\mathrm{I}=60 \mathrm{~min}$ after skin incision, $\mathrm{III}=$ =skin closure) and after hysterectomy.

APE measurements obtained at the two study periods. The accuracy of the isotopic enrichments at isotopic plateau was tested by calculating the coefficient of variation of the three enrichment values. A coefficient of variation $<5 \%$ was used as a confirmation of a valid plateau. The endogenous glucose production $(\mathrm{R}$ glucose $)$ was derived from the formula: $R_{a}=I \cdot\left(A_{a} E_{i n f} /\right.$ $\mathrm{APE}_{\mathrm{pl}}$ - 1), where $\mathrm{APE}_{\text {inf }}$ and $\mathrm{APE}_{\mathrm{pl}}$ are the tracer enrichment in the infusate and plasma at steady state, and $I$ is the tracer infusion rate.

Plasma glucose concentrations were measured using enzymatic assays (Boehringer Mannheim GmbH, Mannheim, Germany). Insulin, glucagon and cortisol were quantified with radioimmunoassays (Diagnostic Products Corporation, Los Angeles, CA,USA, and Behringerwerke AG, Marburg, Germany). For the determination of catecholamines, $5 \mathrm{~mL}$ blood was drawn in Li-heparinate monovettes containing 10 $\mu \mathrm{L} \cdot \mathrm{mL}^{-1}$ of a solution of $61 \mathrm{~g} \cdot \mathrm{L}^{-1}$ glutathione and 76 $\mathrm{g} \cdot \mathrm{L}^{-1}$ EGTA for stabilization. Plasma catecholamine concentrations were measured by reversed phase high performance liquid chromatography (HPLC-ED, Chromakon 500, Kotron, Eiching, Germany) with electrochemical detection. ${ }^{6}$ All blood samples were immediately centrifuged $(3,000 \mathrm{~g}, 15 \mathrm{~min})$ and the obtained plasma was frozen at $-70^{\circ} \mathrm{C}$ until analysis.

\section{Statistics}

Differences between the groups were analyzed using Student's t test. Within-group comparison of variables was made by analysis of variance for repeated measures with post-hoc analysis by the Student-Newman-Keuls test. A probability of $P<0.05$ was considered to be significant. Values are given as means \pm SD.
Results

The two groups were comparable in age (LAVH: $43 \pm$ 8 , VH: $54 \pm 13$ yr), body weight (LAVH: $66 \pm 6, \mathrm{VH}$ : $65 \pm 7 \mathrm{~kg}$ ) and height (LAVH: $163 \pm 6, \mathrm{VH}: 161 \pm 8$ $\mathrm{cm})$. The duration of surgery was significantly longer for LAVH than for VH (LAVH: $143 \pm 38, \mathrm{VH}: 105 \pm$ $22 \mathrm{~min}, P<0.05)$. There was no difference in the amount of piritramide administered for postoperative analgesia (LAVH: $8 \pm 3, \mathrm{VH}: 9 \pm 6 \mathrm{mg}$ ).

Heart rate and mean arterial pressure remained unchanged in both groups, without any differences between groups (Table I). In both groups cardiac output significantly decreased five minutes after skin incision and returned to preoperative values at the end of the operation $(P<0.05)$.

Plasma glucose concentration increased in both groups 60 min after skin incision and remained elevated thereafter $(P<0.05$, Table II $)$. VH induced a higher postoperative plasma glucose concentration than the laparoscopic-assisted approach $(P<0.05)$. Glucose production rate increased in both the LAVH group (from $11.3 \pm 1.3$ to $14.7 \pm 1.5 \mu \mathrm{mol} \cdot \mathrm{kg}^{-1} \cdot \mathrm{min}^{-1}, P$ $<0.05$ ) and the $\mathrm{VH}$ group (from $10.4 \pm 2$ to $14.1 \pm$ $\left.2.7 \mu \mathrm{mol} \cdot \mathrm{kg}^{-1} \cdot \mathrm{min}^{-1}, P<0.05\right)$ without differences between groups. Plasma concentrations of insulin and glucagon did not change significantly during the study period. Plasma cortisol concentrations were significantly more elevated in the transvaginal than in the LAVH group during $(P<0.05)$ and after $(P<0.001)$ surgery. Perioperatively, plasma epinephrine and norepinephrine concentrations increased in all patients without showing significant differences between the two groups.

\section{Discussion}

The results of the present study suggest that LAVH attenuates the hyperglycemic response to surgery when compared to the transvaginal procedure. This finding is in agreement with previous studies showing that minimally invasive surgical techniques blunt the metabolic response to surgical trauma. ${ }^{2}$ Observations based on plasma substrate concentrations alone provide no insight into dynamic metabolic pathways. The higher plasma glucose concentration after $\mathrm{VH}$ could have been the consequence of increased glucose production, decreased glucose utilization or a combination of these events. Because glucose production increased to a similar extent in both groups after surgery, the more accentuated hyperglycemic response to the vaginal procedure must have been due to reduced whole body glucose uptake.

Several factors may account for this phenomenon in the present study. 
TABLE I Hemodynamic variables

\begin{tabular}{|c|c|c|c|c|c|}
\hline & \multirow{2}{*}{$\begin{array}{l}\text { Before } \\
\text { surgery }\end{array}$} & \multicolumn{3}{|c|}{ During surgery } & \multirow{2}{*}{$\begin{array}{l}3 \text { hr after } \\
\text { surgery }\end{array}$} \\
\hline & & $I$ & $I I$ & $I I I$ & \\
\hline \multicolumn{6}{|c|}{ Heart rate (beats. $\mathrm{min}^{-1}$ ) } \\
\hline LAVH & $74 \pm 8$ & $77 \pm 12$ & $80 \pm 14$ & $79 \pm 11$ & $79 \pm 17$ \\
\hline VH & $73 \pm 18$ & $70 \pm 9$ & $74 \pm 8$ & $80 \pm 17$ & $71 \pm 11$ \\
\hline \multicolumn{6}{|c|}{ Mean arterial pressure $(\mathrm{mmHg})$} \\
\hline LAVH & $95 \pm 16$ & $100 \pm 21$ & $94 \pm 13$ & $92 \pm 14$ & $92 \pm 20$ \\
\hline VH & $100 \pm 14$ & $96 \pm 20$ & $90 \pm 14$ & $91 \pm 19$ & $96 \pm 14$ \\
\hline \multicolumn{6}{|c|}{ Cardiac output $\left(L \cdot \mathrm{min}^{-1}\right)$} \\
\hline LAVH & $6.4 \pm 1.6$ & $4.6 \pm 1.1^{*}$ & $5.5 \pm 1.0$ & $5.91 .4 \dagger$ & $7.5 \pm 1.3 \dagger$ \\
\hline VH & $5.3 \pm 0.8$ & $3.9 \pm 0.7^{*}$ & $4.3 \pm 0.9$ & $4.9 \pm 1.3 \dagger$ & $6.1 \pm 1.3 \dagger$ \\
\hline
\end{tabular}

Values are mean $\pm \mathrm{SD}$. LAVH=laparoscopic-assisted vaginal hysterectomy, VH=vaginal hysterectomy.

$\mathrm{I}=$ five minutes, $\mathrm{II}=60 \mathrm{~min}$ after skin incision, $\mathrm{III}=$ skin closure.

${ }^{*} P<0.05$ vs before surgery, $\dagger P<0.05$ vs $\mathrm{I}$.

TABLE II Plasma concentrations of substrates and hormones

\begin{tabular}{|c|c|c|c|c|c|}
\hline & $\begin{array}{l}\text { Before } \\
\text { surgery }\end{array}$ & $I$ & $\begin{array}{l}g \text { surgery } \\
I I\end{array}$ & $I I I$ & $\begin{array}{l}3 \text { hr after } \\
\text { surgery }\end{array}$ \\
\hline \multicolumn{6}{|c|}{ Glucose $\left(\mathrm{mmol}^{-L^{-1}}\right)$} \\
\hline LAVH & $4.1 \pm 0.5$ & $4.7 \pm 0.4$ & $5.9 \pm 0.3^{*}$ & $6.0 \pm 0.6^{*}$ & $6.6 \pm 0.9^{*} \dagger$ \\
\hline VH & $5.0 \pm 1.2$ & $5.1 \pm 0.8$ & $6.4 \pm 1.4^{*}$ & $7.1 \pm 1.7^{*}$ & $8.3 \pm 1.4^{*}$ \\
\hline \multicolumn{6}{|c|}{ Insulin $\left(\mu U \cdot m L^{-1}\right)$} \\
\hline LAVH & $5 \pm 2$ & $4 \pm 3$ & $4 \pm 3$ & $5 \pm 4$ & $6 \pm 4$ \\
\hline VH & $8 \pm 4$ & $6 \pm 2$ & $6 \pm 1$ & $6 \pm 1$ & $12 \pm 9$ \\
\hline \multicolumn{6}{|c|}{ Glucagon $\left(p g \cdot m L^{-1}\right)$} \\
\hline LAVH & $70 \pm 19$ & $67 \pm 27$ & $73 \pm 27$ & $81 \pm 31$ & $72 \pm 16$ \\
\hline $\mathrm{VH}$ & $63 \pm 23$ & $55 \pm 21$ & $78 \pm 26$ & $65 \pm 19$ & $69 \pm 16$ \\
\hline \multicolumn{6}{|c|}{ Cortisol $\left(\mu g \cdot d L^{-1}\right)$} \\
\hline LAVH & $8 \pm 4$ & $14 \pm 12$ & $29 \pm 4^{*} \dagger$ & $30 \pm 6^{*} \dagger$ & $36 \pm 10^{*} \dagger$ \\
\hline \multirow{2}{*}{\multicolumn{6}{|c|}{ Epinephrine $\left(p g \cdot m L^{-1}\right)$}} \\
\hline & & & & & \\
\hline LAVH & $18 \pm 6$ & $97 \pm 41^{*}$ & $162 \pm 134^{*}$ & $295 \pm 235^{*}$ & $98 \pm 54^{*}$ \\
\hline & $31 \pm 17$ & $62 \pm 64$ & $95 \pm 89$ & $133 \pm 100^{*}$ & $165 \pm 82^{*}$ \\
\hline \multicolumn{6}{|c|}{ Norepinephrine $\left(p g \cdot m L^{-1}\right)$} \\
\hline LAVH & $203 \pm 85$ & $324 \pm 122$ & $447 \pm 147^{*}$ & $359 \pm 75^{*}$ & $536 \pm 341^{*}$ \\
\hline VH & $220 \pm 102$ & $326 \pm 156$ & $335 \pm 154$ & $300 \pm 142$ & $426 \pm 202^{*}$ \\
\hline
\end{tabular}

Values are mean $\pm \mathrm{SD}$. LAVH=laparoscopic-assisted vaginal hysterectomy; $\mathrm{VH}=$ vaginal hysterectomy.

$\mathrm{I}=$ five minutes, $\mathrm{II}=60 \mathrm{~min}$ after skin incision, $\mathrm{III}=$ skin closure.

${ }^{*} P<0.05 v s$ before surgery, $\uparrow P<0.05 v s \mathrm{VH}$.

The perioperative endocrine milieu is characterized by increased plasma concentrations of cortisol, epinephrine and norepinephrine. ${ }^{7}$ All of these hormones stimulate glucose production and, by counteracting the action of insulin decrease glucose utilization resulting in hyperglycemia. ${ }^{8}$ As expected, cortisol and catecholamine plasma concentrations significantly increased in the present protocol with both surgical techniques. While epinephrine and norepinephrine plasma concentrations increased similarly after surgery, $\mathrm{VH}$ induced significantly higher intra- and postoperative cortisol plasma concentrations than LAVH.
Cortisol causes insulin resistance by decreasing the rate at which insulin activates the glucose uptake system mediated by a postinsulin receptor block. ${ }^{9}$ Consequently, the stimulated hyperglycemic response after VH can be ascribed to the higher cortisol plasma concentrations. Since there is a positive correlation between the severity of tissue trauma and postoperative plasma cortisol levels, ${ }^{10}$ it seems conceivable that surgical stress induced by VH per se led to a greater activation of the neuroendocrine stress response.

While the vaginal technique requires continuous stretching of the peritoneum by retractors throughout 
the entire operation, this stressful period is shorter with LAVH due to prior laparoscopic dissection of the uterine ligaments. ${ }^{11}$ Hence, one could assume that sustained peritoneal traction during $\mathrm{VH}$ provoked a greater stimulation of afferent nerves and mediator release from the surgical area than the laparoscopicassisted procedure.

The duration of surgical trauma significantly affects perioperative glucose homeostasis with progressive impairment of glucose utilization during prolonged surgery. ${ }^{12,13}$ Even though the duration of surgery was significantly shorter in the $\mathrm{VH}$ group, the transvaginal procedure was associated with a higher plasma glucose concentration further emphasizing the greater stress potential of this surgical approach.

We have to address several limitations of the present investigation, in particular the small sample size and the lack of randomization. LAVH represents a surgical alternative in the presence of factors traditionally considered contraindications to the transvaginal route, i.e., large uterus, limited vaginal access, previous lower abdominal surgery, history of pelvic inflammatory disease, concomitant adnexal masses and nulliparity with lack of uterine descent. Since the choice of surgical technique was entirely left to the attending surgeon, selection bias cannot be excluded in this study. However, in order to minimize bias from factors with known or potential metabolic impact such as duration of surgery ${ }^{12,13}$ and inflammatory disease, patients with an anticipated long duration of surgery (ovarian pathology, previously known dense adhesions, inaccessible uterus) or endometriosis were not admitted to the study protocol.

In conclusion, $\mathrm{VH}$ induced a more pronounced hyperglycemic response than LAVH, which could be ascribed to higher plasma cortisol concentrations. The clinical significance of these findings for surgical patients, particularly for subjects with impaired carbohydrate tolerance or diabetes mellitus warrants further investigation.

\section{References}

1 Schricker T, Lattermann R, Schreiber M, Geisser W, Georgieff $M$, Radermacher $P$. The hyperglycaemic response to surgery: pathophysiology, clinical implications and modification by the anaesthetic technique. Clin Intensive Care 1998; 9: 118-28.

2 Jakeways MSR, Mitchell V, Hashim IA, et al. Metabolic and inflammatory responses after open or laparoscopic cholecystectomy. Br J Surg 1994; 81: 127-31.

3 Reich H, DeCaprio J, McGlynn F. Laparoscopic hysterectomy. J Gynecol Surg 1989; 5: 213-6.

4 Marana R, Busacca M, Zupi E, Garcea N, Paparella P, Catalano GF. Laparoscopically assisted vaginal hys- terectomy versus total abdominal hysterectomy: a prospective, randomized multicenter study. Am J Obstet Gynecol 1999; 180: 270-5.

5 Schricker T, Carli F, Schreiber M, Laftermann R, Georgieff $M$. Time of peritoneal cavity exposure influences postoperative glucose production. Can J Anesth 1999; 46: 352-8.

6 Dirks B, Vorwalter C, Grünert A, Abnefeld FW. Basal plasma-catecholamine-level determination using HPLC-ED and different sample cleanup techniques. Chromatographia 1988; 25: 223-9.

7 Johnston IDA. The metabolic and endocrine response to injury: a review. Br J Anaesth 1973; 45: 252-5.

8 Weissman $C$. The metabolic response to stress: an overview and update. Anesthesiology 1990; 73: $308-27$.

9 Baron AD, Wallace P, Brechtel G. In vivo regulation of non-insulin-mediated and insulin-mediated glucose uptake by cortisol. Diabetes 1987; 36: 1230-7.

10 Traynor C, Hall GM. Endocrine and metabolic changes during surgery: anaesthetic implications. Br J Anaesth 1981; 53: 153-60.

11 Gitsch G, Berger E, Tatra G. Trends in thirty years of vaginal hysterectomy. Surg Gynecol Obstet 1991; 172: 207-10.

2 Tsubo T, Kudo T, Matsuki A, Oyama T. Decreased glucose utilization during prolonged anaesthesia and surgery. Can J Anaesth 1990; 37: 645-9.

13 Iwasaka H, Itoh K, Miyakawa H, Kitano T, Taniguchi $K$, Honda N. Glucose intolerance during prolonged sevoflurane anaesthesia. Can J Anaesth 1996; 43 . 1059-61. 